\title{
Prevalence and survival prognosis of prostate cancer in patients with end-stage renal disease: a retrospective study based on the Korea national database (2003-2010)
}

\author{
Sung Han Kim ${ }^{1, *}$, Jae Young Joung ${ }^{1, *}$, Yoon Seok Suh ${ }^{1}$, Young Ae Kim², Jin Hyuk \\ Hong $^{2}$, Tong Sun Kuark ${ }^{3}$, Eun Sook Lee ${ }^{4}$ and Kang Hyun Lee ${ }^{1}$ \\ ${ }^{1}$ Department of Urology, Center for Prostate Cancer, Research Institute and Hospital of National Cancer Center, Goyang, \\ Korea \\ ${ }^{2}$ Cancer Policy Branch, National Cancer Control Institute, National Cancer Center, Goyang, Korea \\ ${ }^{3}$ Health Insurance Policy Research Institute, National Health Insurance Service, Seoul, Korea \\ ${ }^{4}$ Center for Breast Cancer, Research Institute and Hospital, National Cancer Center, Goyang, Korea \\ *These authors have contributed equally to this work \\ Correspondence to: Kang Hyun Lee, email: uroonco@ncc.re.kr \\ Keywords: prostate cancer, end-stage renal disease, transplantation, prostate-specific antigen, prognosis \\ Received: January 25, $2017 \quad$ Accepted: May 10, $2017 \quad$ Published: July 22, 2017 \\ Copyright: Kim et al. This is an open-access article distributed under the terms of the Creative Commons Attribution License 3.0 \\ (CC BY 3.0), which permits unrestricted use, distribution, and reproduction in any medium, provided the original author and source \\ are credited.
}

\section{ABSTRACT}

Objective: The study was aimed to evaluate the prevalence and prognosis of prostate cancer (PC) and end-stage renal disease (ESRD), determine the risk factors for overall survival (OS) and PC-specific survival (CSS), and evaluate differences in PC-related clinical therapeutic patterns between patients with and without PC-ESRD.

Methods: This observational population study, performed at the National Cancer Center and Cancer Research Institute in Korea, included patients with PC and ESRD from the nationwide Korean Health Insurance System and Korean Central Cancer Registry data. Five-year overall and cancer-specific survival. A joinpoint regression analysis was performed to predict incidence and mortality of PC. Survival was analyzed using Kaplan-Meir curves with log rank tests of patients with dialysis or transplantation.

Results: Of 3945 patients with PC-ESRD, $3.9 \%$ were on dialysis $(\mathrm{N}=152), \mathbf{0 . 2} \%$ had kidney transplantation ( $N=10$, D-TPL group); $3783(95.9 \%)$ had neither dialysis nor transplantation (non-D-TPL ESRD group). There were 697 PC-specific deaths. The median respective OS, PC-specific survival, and 5-year survival rates in the non-ESRD, non-D-TPL ESRD, dialysis ESRD, and transplantation ESRD groups were significantly different $(p<0.001)$. Presence of ESRD, age, body mass index, SEER stage, no treatment within 6 months after diagnosis, no surgery, chemotherapy, radiotherapy or hormonal therapy, non-adenocarcinoma pathology, and Charlson comorbidity index were independent risk factors for OS and CSS.

Conclusions: With a $\mathbf{1 0 . 1 \%}$ nationwide prevalence of PC-ESRD, the presence of ESRD was a significant survival factor along with other significant clinicopathological factors.

\section{INTRODUCTION}

Globally, recent medical improvements have prolonged overall survival (OS) in all disease fields, including end-stage renal disease (ESRD) [1-2].
The enhanced surgical techniques and modern immunosuppression in renal transplantation have led to significant improvements in OS and graft survival, with approximately 35.9 years in the transplant half-life of grafts from living donors and 19.5 years for cadaveric grafts [3]. 
However, despite the necessity of renal transplantation for ESRD, preconditions for organ recipients are multifactorial because of the limited number of available kidneys. One of the conditions for kidney transplantation candidacy is the confirmation of a solid-organ malignancy-free state. To maximize the allocation of resources, the life expectancy of recipients should not be substantially lower than the life of their graft.

Over the past 10 and 15 years, the frequency of recipients older than 50 years has increased by $13 \%$ and $21 \%$, respectively [1,3-6]. Intuitively, this older male population is at a higher risk for prostate cancer (PC). Additionally, the increasing age of kidney transplant recipients, along with the increased age at initiation of dialysis and the documented increase in survival of patients with ESRD with or without dialysis after kidney transplant, has led to a higher number of kidney transplant recipients diagnosed with PC (1.4-5\%) [7] at a two- to five-fold higher incidence than that for the general population [2, $6,8]$. Previous cancer statistics reported that $\mathrm{PC}$ is the second most prevalent solid malignancy in transplantation as well as the most common solid malignancy and the second leading cause of cancer death among American men [9]. Thus, the potential for developing PC has become an important clinical concern because of its morbidity and mortality, particularly because of the increase in number of elderly patients undergoing dialysis and renal transplantation. Additionally, PC-related issues associated with the guidelines for prostate-specific antigen (PSA) screening and standard active modalities of care for patients with ESRD diagnosed with PC (PC-ESRD) have emerged as one of the major issues of debate $[5,10]$.
Disagreements on the screening and treatment guidelines for patients with PC-ESRD have resulted from the lack of information on ESRD in combination with PC. Therefore, it is important to evaluate the clinico-pathological and prognostic characteristics of PC-ESRD, and to analyze the risk factors for OS and PC-specific survival (CSS). No previous studies have reported Asian patients with PC-ESRD, except for one on the epidemiology after transplantation in Taiwan [11]. Therefore, the aims of the present study were to evaluate the prevalence and prognosis of PC-ESRD in Korea, to determine the risk factors for OS and CSS, and to evaluate differences in PC-related clinical therapeutic patterns between patients with and without PC-ESRD.

\section{RESULTS}

The study flow chart is presented in Figure 1. Compared to the non-ESRD groups, the ESRD group was significantly older, with a higher frequency of obese individuals, had an increasingly higher rate of PC diagnoses over time, had more localized PC, was less actively, surgically, and radio-therapeutically treated, had more nonadenocarcinoma histopathology, had a higher grade of CGI, and a higher non-PC-related death rate (all $\mathrm{p}<0.001$; Table 1). Overall, 29,519 (75.8\%) patients were alive at the start of study period, with a median survival time of 37.4 months (0-108.1 months); of these, 2824 (9.6\%) patients with ESRD had a median survival time of 29.9 months (0-108.1 months, Table 1). Among 9406 (24.2\%) deaths, 1121 (11.9\%) patients with ESRD died due to PC-specific deaths $(7.4 \%, \mathrm{~N}=697)$ with a median survival of 2.9 years (Figure 1 ).

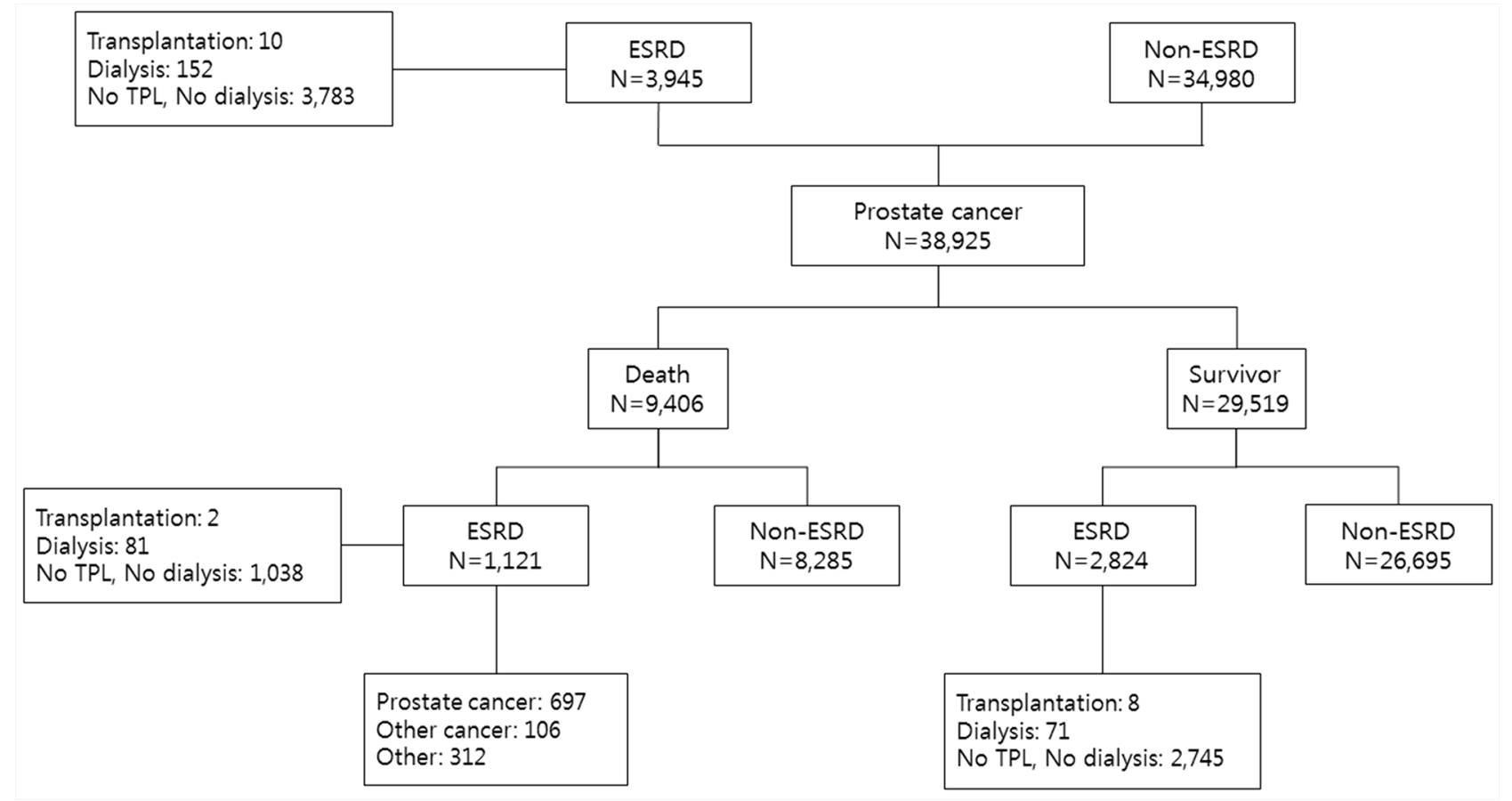

Figure 1: Study flow chart. ESRD, end-stage renal disease; TPL, transplantation; Ca, cancer. 
Table 1: Demographics of patients in the ESRD and non-ESRD groups

\begin{tabular}{|c|c|c|c|c|c|}
\hline \multirow[t]{2}{*}{ Parameter } & \multicolumn{2}{|c|}{$\operatorname{ESRD}(\mathrm{N}=3,945)$} & \multicolumn{2}{|c|}{ Non-ESRD $(\mathrm{N}=\mathbf{3 4 , 9 8 0})$} & \multirow[t]{2}{*}{ P-value } \\
\hline & $\mathbf{N}$ & $\%$ & $\mathbf{N}$ & $\%$ & \\
\hline \multicolumn{6}{|l|}{ Age $(N, \%)$} \\
\hline$<55$ & 95 & 2.41 & 1,503 & 4.30 & $<0.001$ \\
\hline $55-64$ & 735 & 18.63 & 8,897 & 25.43 & \\
\hline $65-74$ & 1,914 & 48.52 & 16,082 & 45.97 & \\
\hline $75<$ & 1,201 & 30.44 & 8,496 & 24.29 & \\
\hline \multicolumn{6}{|l|}{ BMI $\left(\mathrm{kg} / \mathrm{m}^{2}\right)$} \\
\hline Underweight $(<18.5)$ & 62 & 2.54 & 741 & 3.30 & $<0.001$ \\
\hline Normal (18.5 22) & 779 & 31.86 & 7,941 & 35.33 & \\
\hline Overweight (23 24) & 699 & 28.59 & 6,391 & 28.43 & \\
\hline Obesity (25 ) & 905 & 37.01 & 7,403 & 32.94 & \\
\hline \multicolumn{6}{|l|}{ Missing } \\
\hline \multicolumn{6}{|l|}{ Year of cancer diagnosis } \\
\hline 2003 2004 & 354 & 8.97 & 5,353 & 15.30 & $<0.001$ \\
\hline $2005 \sim 2007$ & 1,188 & 30.11 & 11,706 & 33.46 & \\
\hline $2008 \sim 2010$ & 2,403 & 60.91 & 17,921 & 51.23 & \\
\hline \multicolumn{6}{|l|}{ SEER Stage } \\
\hline Localized & 1,974 & 54.97 & 15,572 & 52.56 & $<0.001$ \\
\hline $\begin{array}{l}\text { Regional nodes, both, } \\
\text { NOS }\end{array}$ & 555 & 15.46 & 5,579 & 18.83 & \\
\hline Distant & 324 & 9.02 & 2,722 & 9.19 & \\
\hline Unknown & 738 & 20.55 & 5,754 & 19.42 & \\
\hline \multicolumn{6}{|c|}{ Treatment within 6-month after cancer diagnosis } \\
\hline Yes & 3,234 & 81.98 & 29,632 & 84.71 & $<0.001$ \\
\hline No & 711 & 18.02 & 5,348 & 15.29 & \\
\hline \multicolumn{6}{|l|}{ Surgery treatment } \\
\hline Prostatectomy & 2,120 & 53.74 & 20,486 & 58.56 & $<0.001$ \\
\hline Other & 1,825 & 46.26 & 14,494 & 41.44 & \\
\hline \multicolumn{6}{|l|}{ Chemo treatment } \\
\hline Yes & 780 & 19.77 & 6,952 & 19.87 & 0.8786 \\
\hline No & 3,165 & 80.23 & 28,028 & 80.13 & \\
\hline \multicolumn{6}{|l|}{ Radiation treatment } \\
\hline Yes & 674 & 17.08 & 6,870 & 19.64 & $<0.001$ \\
\hline No & 3,271 & 82.92 & 28,110 & 80.36 & \\
\hline \multicolumn{6}{|l|}{ Hormonal treatment } \\
\hline Yes & 2,024 & 51.31 & 18,443 & 52.72 & 0.0906 \\
\hline No & 1,921 & 48.69 & 16,537 & 47.28 & \\
\hline
\end{tabular}




\begin{tabular}{|c|c|c|c|c|c|}
\hline \multirow[t]{2}{*}{ Parameter } & \multicolumn{2}{|c|}{$\operatorname{ESRD}(N=3,945)$} & \multicolumn{2}{|c|}{ Non-ESRD $(\mathrm{N}=\mathbf{3 4 , 9 8 0})$} & \multirow[t]{2}{*}{ P-value } \\
\hline & $\mathbf{N}$ & $\%$ & $\mathbf{N}$ & $\%$ & \\
\hline \multicolumn{6}{|l|}{ Type of pathology } \\
\hline Adenocarcinoma & 3,063 & 77.64 & 28,011 & 80.08 & 0.0003 \\
\hline Others & 882 & 22.36 & 6,969 & 19.92 & \\
\hline \multicolumn{6}{|l|}{ CCI group } \\
\hline 0 & 166 & 4.21 & 4,848 & 13.86 & $<0.001$ \\
\hline 1 & 506 & 12.83 & 8,304 & 23.74 & \\
\hline 2 & 3,273 & 82.97 & 21,828 & 62.40 & \\
\hline \multicolumn{6}{|l|}{ Death } \\
\hline No & 2,824 & 71.58 & 26,695 & 76.32 & $<0.001$ \\
\hline Yes & 1,121 & 28.42 & 8,285 & 23.68 & \\
\hline \multicolumn{6}{|l|}{ Cause of death } \\
\hline Prostate cancer & 697 & 62.51 & 5,439 & 66.02 & 0.0001 \\
\hline Other cancer & 106 & 9.51 & 944 & 11.46 & \\
\hline Other & 312 & 27.98 & 1,856 & 22.53 & \\
\hline Survival time* & 29.9 & $0-108.0$ & 37.4 & $0-108.1$ & $<0.001$ \\
\hline
\end{tabular}

* Median (range) months.

In the 3945 patients with ESRD, differences in age, body mass index (BMI), time since cancer diagnosis, chemotherapy rate, radiotherapy rate, and treatment rate within 6 months after diagnosis were not significant between the patients without dialysis and transplantation (ND-TPL group) and patients with dialysis or kidney transplantation (D-TPL group). However, compared to the ND-TPL group, the D-TPL group had a significantly higher rate of advanced stage PC, hormonal therapy, and death, while, surgical therapy was performed less frequently in this group $(p<0.001$, Table 2$)$. The median survival times between the D-TPL and ND-TPL groups were 20.2 months (0-107.1 months) and 30.5 months (0-108.0 months), respectively $(\mathrm{p}=0<0.001$, Table 2$)$.

Results of the comparative 5-year OS rate curves showed significant differences between the non-ESRD and ND-TPL groups $(71.3 \%$ vs. $64.5 \%$, hazard ratio [HR] 1.34, 95\% confidence interval [CI] 1.31-1.45), and between the non-ESRD and D-TPL groups $(71.3 \%$ vs. $39.0 \%$, HR 3.57, 95\% CI 2.88-4.43; p $<0.001$; Figure 2). The cancer-specific survival curve showed a significantly similar pattern to the OS curves, as compared to the non-ESRD group (78.8\%), the NDTPL (75.6\%), and D-TPL (55.5\%) groups had lower 5 -year CSS rates $(\mathrm{p}<0.001$, Figure 3$)$.

Results of the adjusted multivariate analysis showed that being in the ESRD group, age, BMI, SEER stage, no treatment within 6 months after diagnosis, prostatectomy, no chemotherapy, no radiation, no hormonal therapy, a non-adenocarcinoma pathology, and CCI group were significant risk factors for OS (Table 3). Further multivariate analysis for prostate-CSS with competing-risks analysis, the ESRD group, age, BMI, SEER stage, no treatment within 6 months after diagnosis, prostatectomy, no chemotherapy, no radiation, no hormonal therapy, a non-adenocarcinoma pathology, and CCI group were significant risk factors for CSS (Table 4).

\section{DISCUSSION}

Studies that have examined the risk and prognosis of PC diagnosed in the cohort of ESRD, particularly transplanted cohorts, are difficult to interpret; in addition, the history of untreated patients with PC-ESRD is not well characterized because of the detection bias introduced by more intensive and routine screening. However, the United States Preventive Services Task Force suggested PSA screening as a grade D recommendation [12]. Additionally, many recent studies have suggested that PSA screening in cases of ESRD is unnecessary due to the increased over diagnosis of clinically insignificant PC, which may not impact survival without treatment, or the common course of chronic immunsuppression after transplantation [7, 13-15]. Similar to our finding of a 
Table 2: Demographics of patients in the D-TPL and ND-TPL groups among those with ESRD

\begin{tabular}{|c|c|c|c|c|c|}
\hline \multirow[t]{2}{*}{ Parameter } & \multicolumn{2}{|c|}{ ND-TPL $(N=3,783)$} & \multicolumn{2}{|c|}{ D-TPL (N=162) } & \multirow[t]{2}{*}{ P-value } \\
\hline & $\mathbf{N}$ & $\%$ & $\mathbf{N}$ & $\%$ & \\
\hline \multicolumn{6}{|l|}{ Age } \\
\hline$<55$ & 92 & 2.4 & 3 & 1.9 & 0.7723 \\
\hline $55-64$ & 706 & 18.7 & 29 & 17.9 & \\
\hline $65-74$ & 1,839 & 48.6 & 75 & 46.3 & \\
\hline $75<$ & 1,146 & 30.3 & 55 & 34.0 & \\
\hline \multicolumn{6}{|l|}{ BMI $\left(\mathrm{kg} / \mathrm{m}^{2}\right)$} \\
\hline Underweight $(<18.5)$ & 58 & 2.4 & 4 & 5.9 & 0.0728 \\
\hline Normal (18.5 22) & 751 & 31.6 & 28 & 41.2 & \\
\hline Overweight (23 24) & 685 & 28.8 & 14 & 20.6 & \\
\hline Obesity (25 ) & 883 & 37.2 & 22 & 32.4 & \\
\hline \multicolumn{6}{|l|}{ Year of cancer diagnosis } \\
\hline $2003 \sim 2004$ & 331 & 8.8 & 23 & 14.2 & 0.0557 \\
\hline $2005 \sim 2007$ & 1,140 & 30.1 & 48 & 29.6 & \\
\hline $2008 \sim 2010$ & 2,312 & 61.1 & 91 & 56.2 & \\
\hline \multicolumn{6}{|l|}{ SEER stage } \\
\hline Localized & 1,922 & 55.7 & 52 & 37.4 & $<0.001$ \\
\hline $\begin{array}{l}\text { Regional extension only, } \\
\text { lymphnodes, both, NOS }\end{array}$ & 537 & 15.6 & 18 & 13.0 & \\
\hline Distant & 296 & 8.6 & 28 & 20.1 & \\
\hline Unknown & 697 & 20.2 & 41 & 29.5 & \\
\hline \multicolumn{6}{|c|}{ Treatment within 6-month after cancer diagnosis } \\
\hline Yes & 3,110 & 82.2 & 124 & 76.5 & 0.0661 \\
\hline No & 673 & 17.8 & 38 & 23.5 & \\
\hline \multicolumn{6}{|l|}{ Surgery treatment } \\
\hline Prostatectomy & 2,065 & 54.6 & 55 & 34.0 & $<0.001$ \\
\hline Other & 1,718 & 45.4 & 107 & 66.1 & \\
\hline \multicolumn{6}{|l|}{ Chemo treatment } \\
\hline Yes & 744 & 19.7 & 36 & 22.2 & 0.4239 \\
\hline No & 3,039 & 80.3 & 126 & 77.8 & \\
\hline \multicolumn{6}{|l|}{ Radiation treatment } \\
\hline Yes & 654 & 17.3 & 20 & 12.4 & 0.1017 \\
\hline No & 3,129 & 82.7 & 142 & 87.7 & \\
\hline \multicolumn{6}{|l|}{ Hormonal treatment } \\
\hline Yes & 1,924 & 50.9 & 100 & 61.7 & 0.0067 \\
\hline No & 1,859 & 49.1 & 62 & 38.3 & \\
\hline
\end{tabular}




\begin{tabular}{|c|c|c|c|c|c|}
\hline \multirow[t]{2}{*}{ Parameter } & \multicolumn{2}{|c|}{ ND-TPL $(N=3,783)$} & \multicolumn{2}{|c|}{ D-TPL (N=162) } & \multirow[t]{2}{*}{ P-value } \\
\hline & $\mathbf{N}$ & $\%$ & $\mathbf{N}$ & $\%$ & \\
\hline \multicolumn{6}{|l|}{ Type of pathology } \\
\hline Adenocarcinoma & 2,946 & 77.9 & 117 & 72.2 & 0.0908 \\
\hline Others & 837 & 22.1 & 45 & 27.8 & \\
\hline \multicolumn{6}{|l|}{ CCI group } \\
\hline 0 & 150 & 4.0 & 16 & 9.9 & 0.0007 \\
\hline 1 & 482 & 12.7 & 24 & 14.8 & \\
\hline $2=<$ & 3,151 & 83.3 & 122 & 75.3 & \\
\hline \multicolumn{6}{|l|}{ Death } \\
\hline No & 2,745 & 72.6 & 79 & 48.8 & $<0.001$ \\
\hline Yes & 1,038 & 27.4 & 83 & 51.2 & \\
\hline \multicolumn{6}{|l|}{ Cause of death } \\
\hline Cancer (prostate) & 649 & 62.9 & 48 & 57.8 & 0.1658 \\
\hline Other cancer & 101 & 9.8 & 5 & 6.0 & \\
\hline Other & 282 & 27.3 & 30 & 36.1 & \\
\hline Survival time* & 30.5 & $0-108.0$ & 20.2 & $0-107.1$ & $<0.001$ \\
\hline
\end{tabular}

* Median (range) months.

$54.0 \%$ localized PC rate in the ESRD group according to the SEER stages (Table 1), most patients with PCESRD have localized PC (53-87.4\%) with a low grade (91\% cT1c, $72 \%$ Gleason sum 6 , and $100 \%$ pT2 at prostatectomy) and excellent outcomes after treatment
(100\% recurrence-free survival) $[5,16]$. Therefore, PC does not affect the overall mortality, but renal failure is the primary survival-determining factor in ESRD; thus, kidney transplantation is the most important survival factor in patients with ESRD [7, 12-15].
A

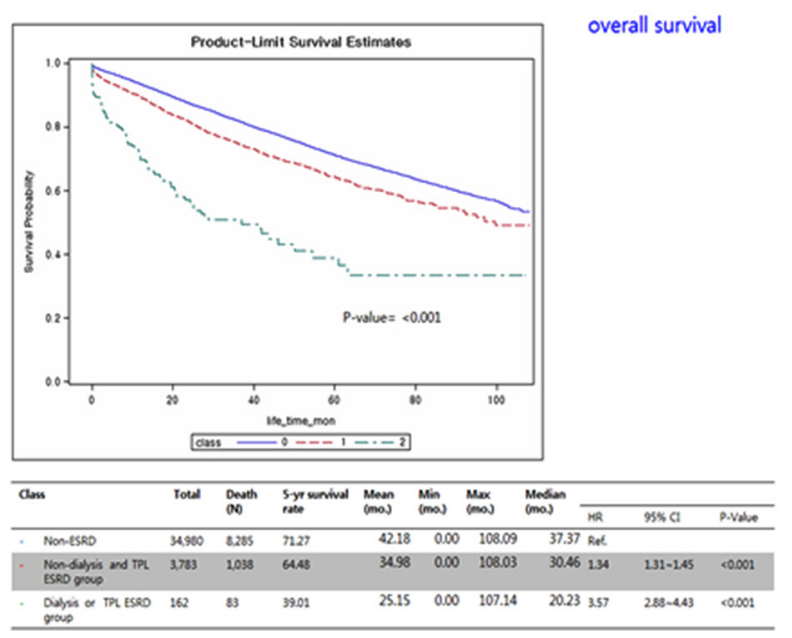

B
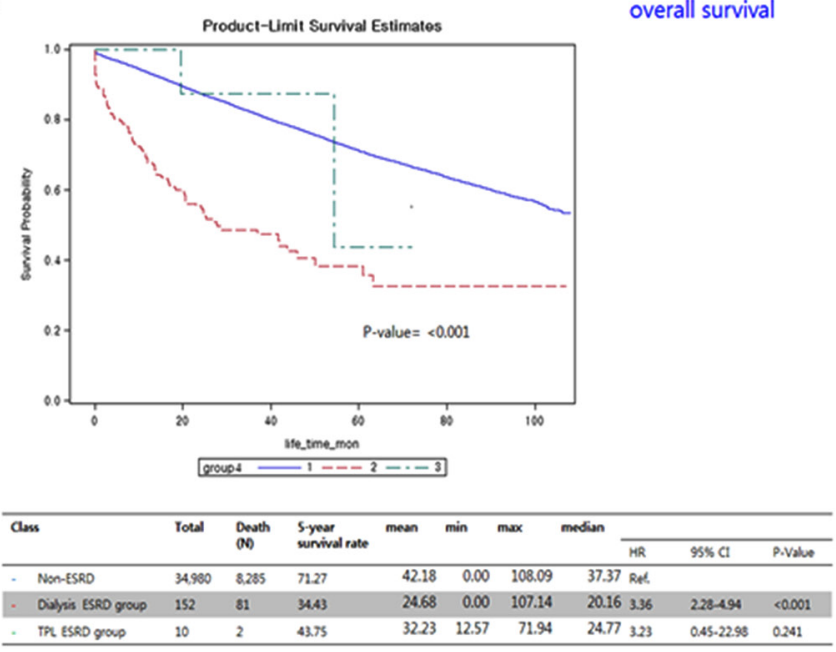

Figure 2: Kaplan-Meier overall survival curves comparing the (A) non-ESRD, ESRD without dialysis and transplantation, and ESRD with dialysis and transplantation groups; and the (B) ESRD without dialysis and transplantation, and ESRD with dialysis and transplantation groups. ESRD, end-stage renal disease; TPL, transplantation; CI, confidence interval; mo., month; HR, hazard ratio. 
As one of the pre-requisite conditions for kidney transplantation is a solid-organ malignancy-free state, patients with PC-ESRD and a positive PSA screening test are ineligible for receiving a kidney transplant until a disease-free state is confirmed; thus, their transplantation priority is delayed. A positive screening result for PC significantly increases transplant wait times by about 2-3.5 fold, especially in ESRD patients less than 69 years old, and $75.8 \%$ of candidates with ESRD and a positive PSA screening result never received a transplant [7]. In the clinical settings, most clinicians (89\%) from 195 United States transplantation centers conducted their routine PSA screening in patients with ESRD, and $73 \%$ of them waited until the patients met the eligibility criteria after treatment [17]. In the present study, a low rate of transplant patients with PC-ESRD $(3.3 \%, \mathrm{~N}=13)$ and a poor CSS time in patients with PC-ESRD on dialysis (29.4 months vs. 24.8 months [TPL-PC-ESRD] vs. 20.2 months [ND-TPL PCESRD]), indirectly implied that patients with PC-ESRD had longer wait times and fewer opportunities of receiving kidney transplants until they achieved a cancer-free state due to the present shortage of grafts $(\mathrm{p}<0.01$, Table 1 ; Figure 2).

The results of our predictive risk analysis showed that D-TPL ESRD and ND-TPL ESRD were significant independent factors of OS (Table 3 ). The results of multivariate analysis for prostate CSS with competingrisks analysis showed that D-TPL ESRD and ND-TPL ESRD were significant independent factors of CSS (Table 4). The D-TPL ESRD group had a significantly higher rate of advanced stage PC (62.6\%) and a worse OS (20.2 months) than the ND-TPL ESRD group (30.5 months), which had an advanced $\mathrm{PC}$ rate of $44.3 \%$ $(\mathrm{p}<0.001$, Tables 1 and 2; Figures 2 and 3). The CSS of patients with PC-ESRD who underwent transplantation
(24.7 months) was similar to that in the non-PC-ESRD group (37.9 months) (Figure 3B); thus, transplanted ESRD patients may be considered as non-ESRD. The American Society of Transplantation recommends physical screening after renal transplantation using a digital rectal examination and PSA screening starting at the age of 50 years in men with a life expectancy of $>10$ years [18]. A recent survey of 195 renal transplantation centers in United States on the practical treatment and screening of PSA in renal transplant patients reported that most clinicians $(89 \%)$ perform routine PSA screening in patients with ESRD using their specific guidelines [17].

Standard treatments can be performed in transplant patients with PC-ESRD ensuing satisfactory results in terms of both the oncological outcomes and graft function, which would be similar to those reported in previous studies. D-TPL ESRD patients and non-D-TPL PC-ESRD patients who are candidates for transplantation and have a survival expectancy of 10 years, should be screened for the risks of PC using active PSA screening, because the survival of these patients is potentially the same as that of the general population. The survival of patients with ESRD should be further analyzed, to stratify patients who benefit from PSA screening. Thus, ESRD patients undergoing dialysis, with a $<10$-year expected survival are not necessarily candidates for PC screening.

An active PC screening, especially in dialysis and transplant patients with ESRD is based on the fact that patients with PC-ESRD usually presented at a more advanced clinical stage and a grade $\geq 2(47-55.3 \%$ and $45 \%$, respectively, in our study). Moreover, they had an increased tumor volume, shown by the percentage of positive biopsy scores, rapid malignant cell proliferation, aggressive biochemical behavior, and a higher susceptibility to infections $[8,19,20]$. Our study also
A

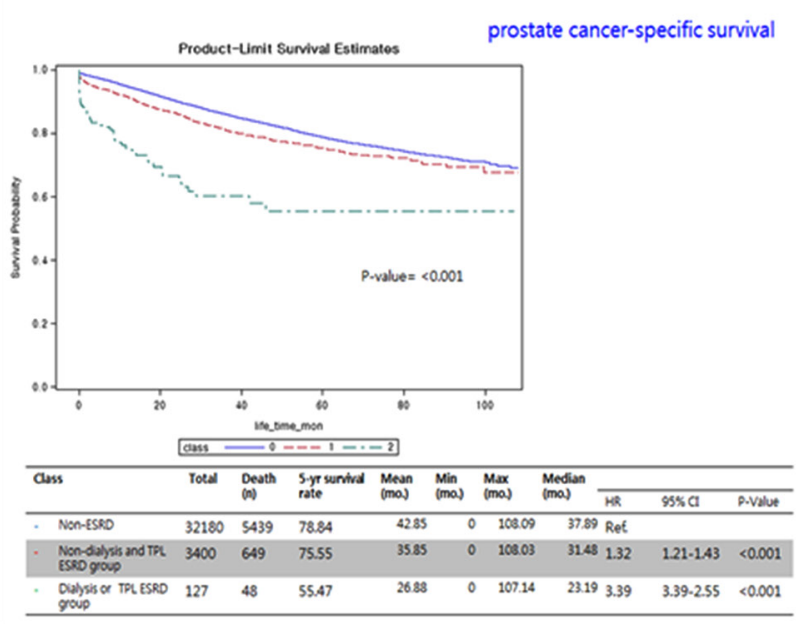

B

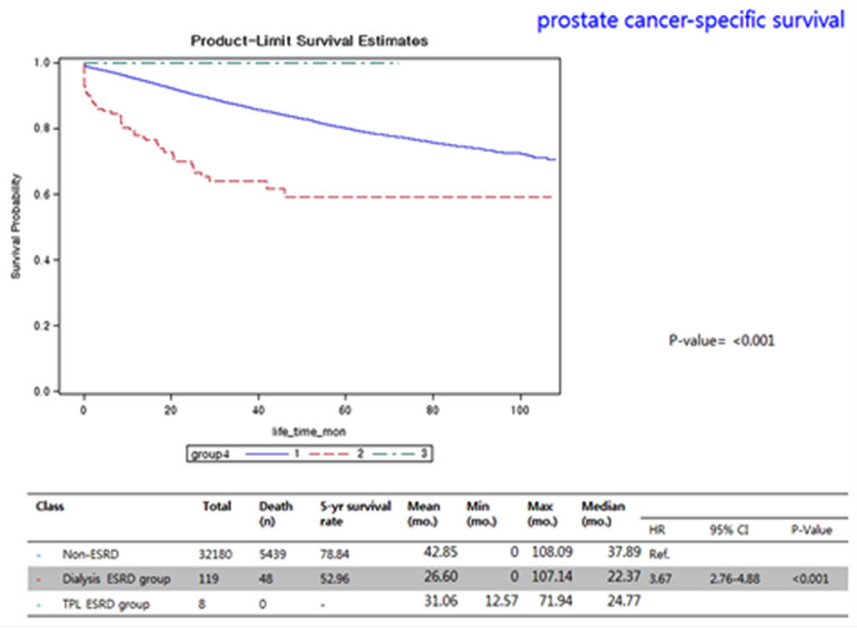

Figure 3: Kaplan-Meier prostate cancer-specific survival curves between the (A) non-ESRD, ESRD without dialysis and transplantation, and ESRD with dialysis and transplantation groups; and (B) non-ESRD, dialysis-ESRD, and TPL-ESRD groups. ESRD, end-stage renal disease; TPL, transplantation; CI, confidence interval; mo., month; HR, hazard ratio. 
Table 3: Results of multivariate analysis for overall survival

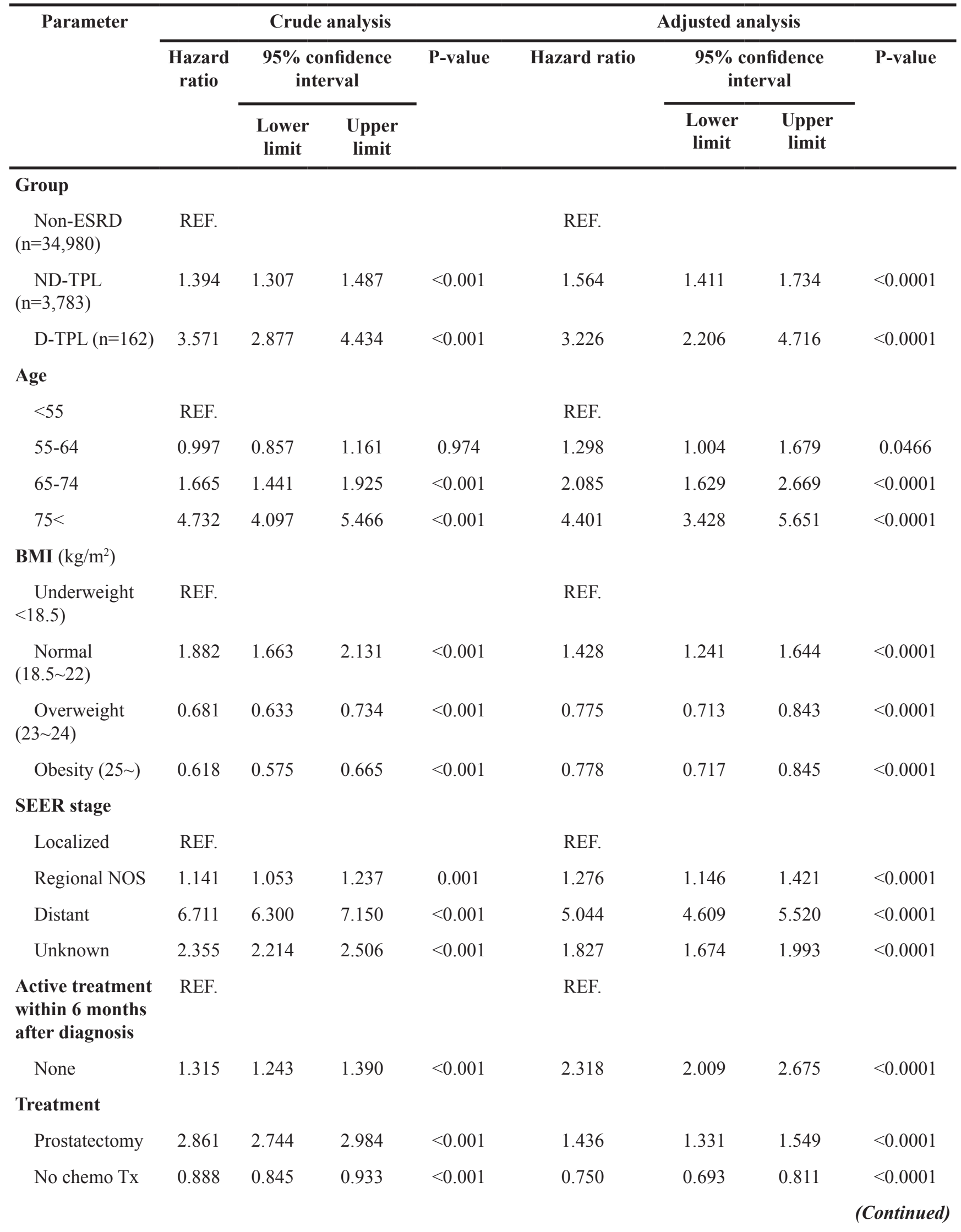




\begin{tabular}{|c|c|c|c|c|c|c|c|c|}
\hline \multirow[t]{3}{*}{ Parameter } & \multicolumn{4}{|c|}{ Crude analysis } & \multicolumn{4}{|c|}{ Adjusted analysis } \\
\hline & \multirow[t]{2}{*}{$\begin{array}{c}\text { Hazard } \\
\text { ratio }\end{array}$} & \multicolumn{2}{|c|}{$\begin{array}{l}95 \% \text { confidence } \\
\text { interval }\end{array}$} & \multirow[t]{2}{*}{ P-value } & \multirow[t]{2}{*}{ Hazard ratio } & \multicolumn{2}{|c|}{$\begin{array}{l}95 \% \text { confidence } \\
\text { interval }\end{array}$} & \multirow[t]{2}{*}{ P-value } \\
\hline & & $\begin{array}{l}\text { Lower } \\
\text { limit }\end{array}$ & $\begin{array}{l}\text { Upper } \\
\text { limit }\end{array}$ & & & $\begin{array}{l}\text { Lower } \\
\text { limit }\end{array}$ & $\begin{array}{l}\text { Upper } \\
\text { limit }\end{array}$ & \\
\hline $\begin{array}{l}\text { No radiation } \\
\mathrm{Tx}\end{array}$ & 0.927 & 0.883 & 0.973 & $<0.001$ & 0.749 & 0.691 & 0.811 & $<0.0001$ \\
\hline $\begin{array}{l}\text { No hormonal } \\
\text { Tx }\end{array}$ & 0.428 & 0.410 & 0.448 & $<0.001$ & 0.465 & 0.417 & 0.519 & $<0.0001$ \\
\hline $\begin{array}{l}\text { Non- } \\
\text { adenocarcinima } \\
\text { pathology } \\
\text { CCI group }\end{array}$ & 1.662 & 1.587 & 1.740 & $<0.001$ & 1.363 & 1.262 & 1.473 & $<0.0001$ \\
\hline 0 & REF. & & & & REF. & & & \\
\hline 1 & 0.598 & 0.562 & 0.636 & $<0.001$ & 0.710 & 0.636 & 0.792 & $<0.0001$ \\
\hline 2 & 0.477 & 0.453 & 0.503 & $<0.001$ & 0.602 & 0.546 & 0.664 & $<0.0001$ \\
\hline
\end{tabular}

showed that $62.6 \%$ of transplanted PC-ESRD patients were diagnosed with locally advanced or advanced PC. In addition, the required immunosuppression after renal allograft transplant may hinder the immune surveillance of PC because of higher susceptibility to tumorigenesis and infections due to an increased incidence of solidorgan malignancy, suggesting a more aggressive disease course. Forty-seven percent of transplant recipients newly diagnosed with PC-ESRD at a minimum of 1 year after transplantation presented with a locally advanced lesion (T3 or T4) [8], and transplanted PC-ESRD recipients with active $\mathrm{PC}$ treatment achieved a longer survival, which may increase PC-specific mortality over an extended period [21].

Regarding the PSA references for biopsies and treatment of PC-ESRD, no established PSA ranges with an age reference to ESRD have been studied to determine susceptible patients with positive PC biopsies compared to the general population $[22,23]$. Additionally, surgery and other curative forms of treatment such as radiation are associated with risks of damaging the allograft after transplantation. Patients with ESRD have higher PSA levels than the general population [22], and prostatectomy after transplantation is technically challenging [24, 25]. Radical prostatectomy is a good treatment option for ESRD before transplantation, because it enables patients with ESRD to achieve objective evidence of biochemical control rapidly post-surgery, which makes them eligible for renal transplantation (disease-free state). However, recent small-scale studies have reported successful treatment outcomes using all treatment modalities, including robotic surgeries [21, 26]. Our study also showed that most of the PC-ESRD patients, especially transplant and dialysis patients, were less frequently treated with surgery than other treatment modalities $(\mathrm{p}<0.05$, Tables 1 and 2$)$. Therefore, standard treatments could be proposed for transplant patients with PC-ESRD to achieve satisfactory results in terms of both, the oncological outcomes and graft function, which is consistent with previous reports.

As with all observational population-based studies, the present study has several limitations. First, although we adjusted for various potential covariates and ICD codes, variables such as lifestyle factors that affect ESRD were not included or routinely captured in a National Institutes of Health (NIH) database, because the database did not capture patients outside of the NIH system. Second, the medical therapies and ESRD patients with failed renal transplantation were not evaluated in terms of survival. Third, any information on the nuclear grades of PC was not obtained, which is important for determining the aggressiveness of PC. Fourth, because of fundamental limitations of this study using huge data with unavailability of clinico-pathological characteristics of patients, including the severity of the disease and tumor burden status in this study. Further prospective studies are needed to verify the poorer survival outcome in, both, OS and CSS in patients with radical prostatectomy found in this study. All the significant prognostic survival factors (OS and CSS), such as Gleason score, treatment interval time after diagnosis, and non-adenocarcinoma pathology were not evaluated in this study because of their unavailability in the National health database.

Despite these limitations, our study offers additional insights into PC-ESRD by extending the evidence to a nationwide cohort, for first time showing the clinical practice trends of diagnosing and treating patients with 
Table 4: Results of multivariate analysis for prostate cancer-specific survival

\begin{tabular}{|c|c|c|c|c|c|c|c|c|c|c|c|c|}
\hline \multirow[t]{3}{*}{ Parameter } & \multicolumn{4}{|c|}{ Crude analysis } & \multicolumn{4}{|c|}{ Adjusted analysis } & \multicolumn{4}{|c|}{ Adjusted analysis* } \\
\hline & \multirow[t]{2}{*}{$\begin{array}{c}\text { Hazard } \\
\text { ratio }\end{array}$} & \multicolumn{2}{|c|}{$\begin{array}{c}95 \% \\
\text { confidence } \\
\text { interval }\end{array}$} & \multirow[t]{2}{*}{ P-value } & \multirow[t]{2}{*}{$\begin{array}{c}\text { Hazard } \\
\text { ratio }\end{array}$} & \multicolumn{2}{|c|}{$\begin{array}{c}95 \% \\
\text { confidence } \\
\text { interval }\end{array}$} & \multirow[t]{2}{*}{ P-value } & \multirow[t]{2}{*}{$\begin{array}{c}\text { Hazard } \\
\text { ratio }\end{array}$} & \multicolumn{2}{|c|}{$\begin{array}{c}95 \% \\
\text { confidence } \\
\text { interval }\end{array}$} & \multirow[t]{2}{*}{ P-value } \\
\hline & & $\begin{array}{c}\text { Lower } \\
\text { limit }\end{array}$ & $\begin{array}{l}\text { Upper } \\
\text { limit }\end{array}$ & & & $\begin{array}{l}\text { Lower } \\
\text { limit }\end{array}$ & $\begin{array}{l}\text { Upper } \\
\text { limit }\end{array}$ & & & $\begin{array}{l}\text { Lower } \\
\text { limit }\end{array}$ & $\begin{array}{l}\text { Upper } \\
\text { limit }\end{array}$ & \\
\hline \multicolumn{13}{|l|}{ Group } \\
\hline $\begin{array}{l}\text { Non-ESRD } \\
(\mathrm{n}=34,980)\end{array}$ & REF. & & & & REF. & & & & REF. & & & \\
\hline $\begin{array}{l}\text { ND-TPL } \\
(n=3,783)\end{array}$ & 1.298 & 1.298 & 1.408 & $<0.001$ & 1.573 & 1.380 & 1.794 & $<0.0001$ & 1.488 & 1.295 & 1.708 & $<0.0001$ \\
\hline D-TPL $(n=162)$ & 3.021 & 2.274 & 4.014 & $<0.001$ & 2.503 & 1.478 & 4.238 & 0.0006 & 2.050 & 1.172 & 3.588 & 0.0119 \\
\hline \multicolumn{13}{|l|}{ Age } \\
\hline$<55$ & REF. & & & & REF. & & & & REF. & & & \\
\hline $55-64$ & 0.879 & 0.744 & 1.037 & 0.1269 & 1.167 & 0.884 & 1.541 & 0.2745 & 1.162 & 0.898 & 1.504 & 0.2535 \\
\hline $65-74$ & 1.232 & 1.052 & 1.444 & 0.0098 & 1.604 & 1.229 & 2.093 & 0.0005 & 1.564 & 1.223 & 2.002 & 0.0004 \\
\hline $75<$ & 3.483 & 2.976 & 4.078 & $<0.001$ & 3.285 & 2.507 & 4.305 & $<0.0001$ & 3.024 & 2.346 & 3.897 & $<0.0001$ \\
\hline \multicolumn{13}{|l|}{ BMI $\left(\mathrm{kg} / \mathrm{m}^{2}\right)$} \\
\hline $\begin{array}{l}\text { Underweight } \\
<18.5 \text { ) }\end{array}$ & REF. & & & & REF. & & & & REF. & & & \\
\hline $\begin{array}{r}\text { Normal } \\
(18.5 \sim 22)\end{array}$ & 1.874 & 1.607 & 2.186 & $<0.001$ & 1.519 & 1.280 & 1.802 & $<0.0001$ & 1.492 & 1.234 & 1.802 & $<0.0001$ \\
\hline $\begin{array}{l}\text { Overweight } \\
(23 \sim 24)\end{array}$ & 0.671 & 0.611 & 0.736 & $<0.001$ & 0.762 & 0.686 & 0.847 & $<0.0001$ & 0.776 & 0.696 & 0.865 & $<0.0001$ \\
\hline Obesity $(25 \sim)$ & 0.618 & 0.564 & 0.676 & $<0.001$ & 0.773 & 0.699 & 0.856 & $<0.0001$ & 0.790 & 0.712 & 0.876 & $<0.0001$ \\
\hline \multicolumn{13}{|l|}{ SEER stage } \\
\hline Localized & REF. & & & & REF. & & & & REF. & & & \\
\hline Regional NOS & 1.401 & 1.261 & 1.557 & 0.001 & 1.509 & 1.308 & 1.741 & $<0.0001$ & 1.489 & 1.292 & 1.717 & $<0.0001$ \\
\hline Distant & 11.234 & 10.387 & 12.150 & $<0.001$ & 7.922 & 7.075 & 8.870 & $<0.0001$ & 7.626 & 6.772 & 8.587 & $<0.0001$ \\
\hline Unknown & 3.081 & 2.839 & 3.344 & $<0.001$ & 2.314 & 2.058 & 2.601 & $<0.0001$ & 2.298 & 2.041 & 2.587 & $<0.0001$ \\
\hline $\begin{array}{l}\text { Active treatment } \\
\text { within } 6 \text { months } \\
\text { after diagnosis, } \\
\text { Yes }\end{array}$ & REF. & & & & REF. & & & & REF. & & & \\
\hline None & 1.299 & 1.212 & 1.392 & $<0.001$ & 3.464 & 2.837 & 4.229 & $<0.0001$ & 3.264 & 2.690 & 3.959 & $<0.0001$ \\
\hline \multicolumn{13}{|l|}{ Treatment } \\
\hline Prostatectomy & 3.150 & 2.988 & 3.321 & $<0.001$ & 1.443 & 1.315 & 1.584 & $<0.0001$ & 1.410 & 1.279 & 1.554 & $<0.0001$ \\
\hline No chemo Tx & 1.010 & 0.948 & 1.077 & 0.7494 & 0.846 & 0.764 & 0.937 & 0.0013 & 0.878 & 0.790 & 0.977 & 0.0166 \\
\hline No radiation $\mathrm{Tx}$ & 0.749 & 0.708 & 0.793 & $<0.001$ & 0.630 & 0.572 & 0.693 & $<0.0001$ & 0.610 & 0.553 & 0.673 & $<0.0001$ \\
\hline $\begin{array}{l}\text { No hormonal } \\
\text { Tx }\end{array}$ & 0.341 & 0.322 & 0.361 & $<0.001$ & 0.312 & 0.265 & 0.367 & $<0.0001$ & 0.313 & 0.265 & 0.370 & $<0.0001$ \\
\hline
\end{tabular}




\begin{tabular}{|c|c|c|c|c|c|c|c|c|c|c|c|c|}
\hline \multirow[t]{3}{*}{ Parameter } & \multicolumn{4}{|c|}{ Crude analysis } & \multicolumn{4}{|c|}{ Adjusted analysis } & \multicolumn{4}{|c|}{ Adjusted analysis* } \\
\hline & \multirow[t]{2}{*}{$\begin{array}{l}\text { Hazard } \\
\text { ratio }\end{array}$} & \multicolumn{2}{|c|}{$\begin{array}{c}95 \% \\
\text { confidence } \\
\text { interval }\end{array}$} & \multirow[t]{2}{*}{ P-value } & \multirow[t]{2}{*}{$\begin{array}{c}\text { Hazard } \\
\text { ratio }\end{array}$} & \multicolumn{2}{|c|}{$\begin{array}{c}95 \% \\
\text { confidence } \\
\text { interval }\end{array}$} & \multirow[t]{2}{*}{ P-value } & \multirow[t]{2}{*}{$\begin{array}{c}\text { Hazard } \\
\text { ratio }\end{array}$} & \multicolumn{2}{|c|}{$\begin{array}{c}95 \% \\
\text { confidence } \\
\text { interval }\end{array}$} & \multirow[t]{2}{*}{ P-value } \\
\hline & & $\begin{array}{l}\text { Lower } \\
\text { limit }\end{array}$ & $\begin{array}{l}\text { Upper } \\
\text { limit }\end{array}$ & & & $\begin{array}{c}\text { Lower } \\
\text { limit }\end{array}$ & $\begin{array}{l}\text { Upper } \\
\text { limit }\end{array}$ & & & $\begin{array}{l}\text { Lower } \\
\text { limit }\end{array}$ & $\begin{array}{l}\text { Upper } \\
\text { limit }\end{array}$ & \\
\hline $\begin{array}{l}\text { Non- } \\
\text { adenocarcinima } \\
\text { pathology } \\
\text { CCI group }\end{array}$ & 1.805 & 1.708 & 1.908 & $<0.001$ & 1.428 & 1.300 & 1.569 & $<0.0001$ & 1.387 & 1.257 & 1.530 & $<0.0001$ \\
\hline 0 & REF. & & & & REF. & & & & REF. & & & \\
\hline 1 & 0.541 & 0.504 & 0.581 & $<0.001$ & 0.667 & 0.587 & 0.757 & $<0.0001$ & 0.679 & 0.594 & 0.776 & $<0.0001$ \\
\hline 2 & 0.361 & 0.339 & 0.384 & $<0.001$ & 0.502 & 0.448 & 0.563 & $<0.0001$ & 0.512 & 0.453 & 0.578 & $<0.0001$ \\
\hline
\end{tabular}

* Competing-risks analysis.

PC-ESRD, as well as that D-TPL and ND-TPL ESRD are significant prognostic factors of OS and CSS.

In conclusion, this is the first study to present the nationwide prevalence of $\mathrm{PC}$ in patients with ESRD $(10.1 \%)$ in Korea, and the fact that presence of ESRD in patients, irrespective of with or without dialysis or kidney transplantation is a significant survival factor along with other significant clinico-pathological factors. Further investigations on PC-ESRD patients who have undergone kidney transplantation are needed to better understand optimal screening methods to avoid overtreatment and under treatment in this unique and challenging patient population.

\section{MATERIALS AND METHODS}

This study was approved by the Institutional Review Board (IRB) of the National Cancer Center and Cancer Research Institute in Korea (IRB no.: NCC1310250. The database and methodology of cancer statistics have been described in detail elsewhere; additionally, the database has been the source for numerous epidemiological studies [27] that used cancer incidence and mortality data from 2002 to 2012 from the Korean National Health Insurance System of Statistics Korea [27] and the Korea National Cancer Incidence Database of Korean Central Cancer Registry [28].

\section{Study population}

PC diagnosis was based on the International Classification of Diseases, Tenth Edition (ICD-10) diagnosis code (C61) in the Korean Central Cancer Registry between 2003 and 2010. Population data from 2002 to 2011 were obtained from the resident registration population, as reported by Statistics Korea. Due to the time required for data collection, compilation, quality control and analysis, the incidence and mortality data for a specific year are usually available at least 1 year later. Therefore, 38,925 patients with complete medical records, including survival data from the Korean National Health Insurance System until follow-up in 2011, were screened.

The Surveillance, Epidemiology, and End Results (SEER) staging classification was used to stage PC. Diagnostic ICD-10 codes for diabetes (E10.2, E11.2, E12.2, E13.2, and E14.2), renal failure (N17.0, N17.1, N17.2, N17.8, N17, N18, N19, N99.0, T79.5, I13.1, I13.2, I12.0, I12.9, and E87.2), dialysis (Z99.2, Z49.0, Z49.1, Z49.2, N18.5, T85.6, T82.8, T82.4, Y60.2, Y61.2, Y84.1, and E85.3), and kidney transplantation (Z94.0 and T86.1) were used to select $3945(10.1 \%)$ patients with ESRD before they were diagnosed with PC; these subjects were enrolled in the study (ESRD group). Patients with secondary malignancies were excluded from our study.

\section{Statistical analysis}

The Students t-test, chi-square test, and Fisher exact test were used to compare differences between groups. To predict the incidence and mortality of PC, we first performed a joinpoint regression analysis on available data to determine the year when significant changes occurred in cancer trends according to presence and absence of ESRD (e.g., dialysis, renal transplantation, and no dialysis or transplantation). The survival analysis was performed using Kaplan-Meier curves with log-rank tests of $162(4.1 \%)$ patients with dialysis or kidney transplantation (D-TPL group), and 3783 (95.9\%) without dialysis and transplantation (ND-TPL group). A competing-risks analysis was adapted in the multivariate analysis for CSS. Two-sided $\mathrm{p}$-values $<0.05$ were considered statistically significant. All statistical analyses were performed using SAS 9.4 (SAS Institute, Cary, NC, USA). 


\section{Abbreviations}

CCI, Charlson comorbity index

$\mathrm{PC}$, prostate cancer

ESRD, end-stage renal disease

PSA, prostate-specific antigen

BMI, body mass index

PC-ESRD, prostate cancer patient with end stage renal disease

SEER, Surveillance, Epidemiology, and End Results

IRB, Institutional Review Board

$\mathrm{NIH}$, National Institutes of Health

D-TPL, patients with dialysis or kidney transplantation

ND-TPL, patients without dialysis and transplantation

ND-TPL ESRD, end-stage renal disease patients without dialysis and transplantation

OS, overall survival

CSS, cancer-specific survival

\section{Author contributions}

Study concept and design: Sung Han Kim, Jae Young Joung, Eun Sook Lee, Kang Hyun Lee.

Acquisition of data: Sung Han Kim, Young Ae Kim, Jin Hyuk Hong, Tong Sun Kuark.

Analysis and interpretation of data: Sung Han Kim, Jae Young Joung, Yoon Seok Suh, Young Ae Kim.

Drafting of the manuscript: Sung Han Kim, Jae Young Joung, Yoon Seok Suh.

Critical revision of the manuscript for important intellectual content: Sung Han Kim, Jae Young Joung, Yoon Seok Suh, Young Ae Kim, Kang Hyun Lee.

Statistical analysis: Young Ae Kim, Jin Hyuk Hong. Obtaining funding: Eun Sook Lee.

Administrative, technical, or material support: Young Ae Kim, Jin Hyuk Hong, Tong Sun Kuark, Eun Sook Lee, Kang Hyun Lee.

Supervision: Eun Sook Lee, Kang Hyun Lee.

Other (specify): None.

\section{ACKNOWLEDGMENTS}

None.

\section{CONFLICTS OF INTEREST}

All of authors declare no conflicts of interest in this study.

\section{FUNDING}

This work was supported by grants from the National Cancer Center (No.1310250 and 1532200), Republic of Korea.

\section{REFERENCES}

1. Hariharan S, Johnson CP, Bresnahan BA, Taranto SE, McIntosh MJ, Stablein D. Improved graft survival after renal transplantation in the United States, 1988 to $1996 . \mathrm{N}$ Eng J Med. 2000; 342: 605-612.

2. Abramowicz D, Cochat P, Claas FH, Heemann U, Pascual J, Dudley C, Harden P, Hourmant M, Maggiore U, Salvadori M, Spasovski G, Squifflet JP, Steiger J, et al. European Renal Best Practice Guideline on kidney donor and recipient evaluation and perioperative care. Nephrol Dial Transplant. 2015; 30: 1790-1797.

3. Kessler M, Jay N, Molle R, Guillemin F. Excess risk of cancer in renal transplant patients. Transpl Int. 2006; 19: 908-914.

4. Penn I. Occurrence of cancers in immunosuppressed organ transplant recipients. Clin Transpl. 1998; 12: 147-158.

5. Port FK, Merion RM, Goodrich NP, Wolfe RA. Recent trends and results for organ donation and transplantation in the United States, 2005. Am J Transplant. 2006; 6: 1095-1100.

6. Kleinclauss F, Gigante M, Neuzillet Y, Mouzin M, Terrier N, Salomon L, Iborra F, Petit J, Cormier L, Lechevallier E; Renal Transplantation Committee of the French Urological Association (AFU). Prostate cancer in renal transplant recipients. Nephrol Dial Transplant. 2008; 23: 2374-2380.

7. Port FK, Ragheb NE, Schwartz AG, Hawthorne VM. Neoplasms in dialysis patients: a population-based study. Am J Kidney Dis. 1989; 14: 119-123.

8. Siegel RL, Miller KD, Jemal A. Cancer statistics, 2016. CA Cancer J Clin. 2016; 66: 7-30.

9. Oniscu GC, Brown H, Forsythe JL. Impact of cadaveric renal transplantation on survival in patients listed for transplantation. J Am Soc Nephrol. 2005; 16: 1859-1865.

10. Hsiao FY, Hsu WW. Epidemiology of post-transplant malignancy in Asian renal transplant recipients: a population-based study. Int Urol Nephrol. 2014; 46: 833-838.

11. Jung KW, Won YJ, Oh CM, Kong HJ, Cho H, Lee JK, Lee $\mathrm{DH}$, Lee KH. Prediction of cancer incidence and mortality in Korea, 2016. Cancer Res Treat. 2016; 48: 451-457.

12. Andriole GL, Crawford ED, Grubb RL 3rd, Buys SS, Chia D, Church TR, Fouad MN, Isaacs C, Kvale PA, Reding DJ, Weissfeld JL, Yokochi LA, O'Brien B, et al. Prostate cancer screening in the randomized Prostate, Lung, Colorectal, and Ovarian Cancer Screening Trial: mortality results after 13 years of follow-up. J Natl Cancer Inst. 2012; 104: 125-132.

13. Carlsson SV, Holmberg E, Moss SM, Roobol MJ, Schröder FH, Tammela TL, Aus G, Auvinen AP, Hugosson J. No excess mortality after prostate biopsy: results from the European Randomized Study of Screening for Prostate Cancer. BJU Int. 2011; 107: 1912-1917.

14. Schröder FH, Hugosson J, Roobol MJ, Tammela TL, Ciatto S, Nelen V, Kwiatkowski M, Lujan M, Lilja H, Zappa M, 
Denis LJ, Recker F, Berenguer A, et al. Screening and prostate-cancer mortality in a randomized European study. N Engl J Med. 2009; 360: 1320-1328.

15. Vitiello GA, Sayed BA, Wardenburg M, Perez SD, Keith CG, Canter DJ, Ogan K, Pearson TC, Turgeon N. Utility of prostate cancer screening in kidney transplant candidates. $\mathrm{J}$ Am Soc Nephrol. 2016; 27: 2157-2163.

16. Luján M, Páez A, Angulo JC, Granados R, Nevado M, Torres GM, Berenguer A. Prostate cancer incidence and mortality in the Spanish section of the European Randomized Study of Screening for Prostate Cancer (ERSPC). Prostate Cancer Prostatic Dis. 2014; 17: 187-191.

17. Gin GE, Pereira JF, Weinberg AD, Mehrazin R, Lerner SM, Sfakianos JP, Phillips CK. Prostate-specific antigen screening and prostate cancer treatment in renal transplantation candidates: a survey of U.S. transplantation centers. Urol Oncol. 2016; 34: 57.e9-13.

18. Kasiske BL, Cangro CB, Hariharan S, Hricik DE, Kerman RH, Roth D, Rush DN, Vazquez MA, Weir MR; American Society of Transplantation. The evaluation of renal transplantation candidates: clinical practice guidelines. Am J Transplant. 2001; 1: 3-95.

19. Kurahashi T, Miyake H, Shinozaki M, Oka N, Takenaka A, Hara I, Matsumura Y, Fujisawa M. Screening for prostate cancer using prostate-specific antigen testing in Japanese men on hemodialysis. Int Urol Nephrol. 2008; 40: 345-349.

20. Taneja S, Mandayam S, Kayani ZZ, Kuo YF, Shahinian VB. Comparison of stage at diagnosis of cancer in patients who are on dialysis versus the general population. Clin J Am Soc Nephrol. 2007; 2: 1008-1013.

21. Breyer BN, Whitson JM, Freise CE, Meng MV. Prostate cancer screening and treatment in the transplant population: current status and recommendations. J Urol. 2009; 181: 2018-2025; discussion 25-26.
22. Chen CJ, Heldt JP, Anderson KM, Ruckle HC, Agarwal G, Smith DL, Schlaifer AE, Richards GD, Arnold DC 2nd, Baldwin DD. Prostate specific antigen levels and prostate cancer detection rates in patients with end stage renal disease. J Urol. 2012; 187: 2061-2065.

23. Oesterling JE, Jacobsen SJ, Chute CG, Guess HA, Girman CJ, Panser LA, Lieber MM. Serum prostate-specific antigen in a community-based population of healthy men. Establishment of age-specific reference ranges. JAMA. 1993; 270: 860-864.

24. Diller R, Gruber A, Wolters H, Senninger N, Spiegel HU. Therapy and prognosis of tumors of the genitourinary tract after kidney transplantation. Transplant Proc. 2005; 37: 2089-2092.

25. Mouzin M, Bachaud JM, Kamar N, Gamé X, Vaessen C, Rischmann P, Rostaing L, Malavaud B. Three-dimensional conformal radiotherapy for localized prostate cancer in kidney transplant recipients. Transplantation. 2004; 78: 1496-1500.

26. Pettenati C, Jannot AS, Hurel S, Verkarre V, Kreis H, Housset M, Legendre C, Méjean A, Timsit MO. Prostate cancer characteristics and outcome in renal transplant recipients: results from a contemporary single center study. Clin Transplant. 2016; 30: 964-971.

27. Shin HR, Won YJ, Jung KW, Kong HJ, Yim SH, Lee JK, Noh HI, Lee JK, Pisani P, Park JG; Members of the Regional Cancer Registries. Nationwide cancer incidence in Korea, 1999 2001; first result using the national cancer incidence database. Cancer Res Treat. 2005; 37: 325-331.

28. Moyer VA; U.S. Preventive Services Task Force. Screening for prostate cancer: U.S. Preventive Services Task Force recommendation statement. Ann Intern Med. 2012; 157: 120-134. 